\title{
Evaluation of Three Common Algorithms for Structure Active Control
}

\author{
Mohammad Sareban \\ Department of Civil Engineering \\ Shahrood Branch, Islamic Azad University \\ Shahrood, Iran
}

\begin{abstract}
Recently active structure controllers were considered to deal with the impact of earthquake forces and the result of the investigations provided multiple algorithms to calculate force control and many different ways to apply these forces on the structure. In this study, the efficiency and effectiveness of three methods (linear quadratic regulator, fuzzy logic and pole assigning) are investigated. In addition, three buildings with different height classes with an active tuned mass damper (ATMD) on the top floor are considered to compare the active control methods. Examples with known mass and stiffness and with variable mass are considered. The results show that all three control methods used for the ATMD device reduce the structural response. The fuzzy control method, caused a sharp decline in relative displacement of building floors up to $80 \%$. But in LQR and pole allocation procedures the applied force is limited. The best performance of fuzzy control is for high-rise buildings. The three different methods of control are stable in different masses and even under a random change of floor masses, their effectiveness can be trusted.
\end{abstract}

Keywords-active control; configurable active mass damper; linear quadratic optimal control; fuzzy control; pole allocation control; uncertainty.

\section{INTRODUCTION}

Controlling wind or seismic induced vibrations can be performed by passive, active, semi-active or combined control systems. Each of these control systems uses various instruments to reduce seismic responses. As semi-active systems are reliable as passive systems and adaptive as active systems, they have attracted the attention of many researchers in the structural control field. Active control systems, in contrast to passive systems, require an external energy for their operation. Active control systems can be mainly divided into force applying mechanisms and algorithms to calculate the control force. Although reducing damage caused by large loads is the main target in structural engineering, little attention has been given to directly control damage parameters. This is because valid damage parameters involve various variables while modern control theories, such as LQR, LQG, sliding mode control based on state space models, have the ability to involve state variables in the performance index. Many researchers have studied the use of different control algorithms and tools in order to reduce response and improve the behavior of structures and achieved good results. In [1], authors provided an overview of modeling and controlling structures. They raised advancements in the field of modeling and seismic structural control and considered a variety of control methods including linear control, nonlinear control and intelligent control. In [2], authors investigated the application of an active system in vibration control of three and two-floor non-linear structures. Due to the nonlinear behavior of the structure, researchers used fuzzy control to determine the control force. In [3], authors used a fuzzy control system and an active mass damper (ATMD) to shield buildings against earthquakes.

\section{MATERIALS AND METHODS}

\section{A. Active Control of Structures}

An active control system is made from an external power source or hydraulic or electromechanical actuator force that applies a predetermined force to the structure. Such forces can be used to attract or waste energy. The function of this system is based on measures by sensitive receptors that have been installed in floors and are sent to the CPU for processing. Then, based on a predetermined control algorithm, the optimal controlling force is decided. The control process starts when the measured amplitude of oscillations is equal to or greater than a preset limit. Such an approach is considered to bear increased efficiency compared to passive control strategies [4].

\section{1) Damper with variable mass}

This system is a modified form of a damper with coordinated mass in which, an additional object with a driver is connected to the primary system. Thus, there is a renewed impetus in system that complements the generated force by the coordinated mass and increase the damping force of the system.

\section{2) Linear quadratic method regulator (LQR) 2}

LQR equations are one of the most widely used optimization algorithms for active control. The equation of multi-floor building's motion as a shear frame model with controller is as follows:

$$
M^{*} x(t)+C^{*} \dot{x}(t)+K^{*} x(t)=-\eta x_{g}(t)+\Gamma U(t)
$$

After obtaining the solution to (1), the equation of motion is transferred to state-space. 


$$
\dot{\mathrm{Z}}(\mathrm{t})=\mathrm{AZ}(\mathrm{t})+\mathrm{B}_{\mathrm{u}} \mathrm{U}(\mathrm{t})+\mathrm{B}_{\mathrm{r}} \mathrm{x}_{g}(\mathrm{t})
$$

In LQR procedure the below energy integral should be minimal:

$$
J=\int_{0}^{t_{1}}\left(Z^{T} Q Z+U^{T} R U\right) d t
$$

If the matrix $\mathrm{Q}$ is large, structural response will be less and control force increases. If $\mathrm{R}$ is large, the response of the structure is high and control force decrease. The control force can be obtained from (4). As can be seen, the control force is linked to the structural response. If the structure response is large, more control force is applied respectively. The ontrol force $\mathrm{U}(\mathrm{t})$ can be obtained from the following equation:

$$
\mathrm{U}(\mathrm{t})=-\mathrm{GZ}(\mathrm{t})=-\mathrm{R}^{-1} \mathrm{~B}_{\mathrm{u}}{ }^{\mathrm{T}} \mathrm{PZ}(\mathrm{t})
$$

In which, $G$ is the gain matrix and $P$ is a matrix obtained from nonlinear Rikati equation. By combining (2) and (4) we have:

$$
\dot{Z}(\mathrm{t})=\mathrm{AZ}(\mathrm{t})+\mathrm{B}_{\mathrm{u}}\left(-\mathrm{R}^{-1} \mathrm{~B}_{\mathrm{u}}{ }^{\mathrm{T}} \mathrm{PZ}(\mathrm{t})\right)+\mathrm{B}_{\mathrm{r}} \mathrm{f}(\mathrm{t})
$$

Considering $A^{*}=A-B_{u} R^{(-1)} B_{u}{ }^{T} P$ we have:

$$
\dot{Z}(\mathrm{t})=\mathrm{A}^{*} \mathrm{Z}(\mathrm{t})+\mathrm{B}_{\mathrm{r}} \mathrm{f}(\mathrm{t})
$$

To solve in state space we need the following equation:

$$
\mathrm{y}=\mathrm{EZ}(\mathrm{t})+\operatorname{Lf}(\mathrm{t})
$$

\section{3) Fuzzy control}

The fuzzy control algorithm is based on fuzzy logic and uses intuition and knowledge of experts instead of differential equations to explain the behavior of a system [5] and in this case to determine the control force. There are many ways to generate fuzzy rules that include logical reasoning, and learning tests and simulations of the sample. So the control using this method is naturally robust and yet simple. To get answers to the equation (1), the equation of motion is transmitted to state-space.

$$
\dot{\mathrm{Z}}(\mathrm{t})=\mathrm{AZ}(\mathrm{t})+\mathrm{B}_{\mathrm{u}} \mathrm{U}(\mathrm{t})+\mathrm{B}_{\mathrm{r}} \mathrm{x}_{g}(\mathrm{t})
$$

To conduct a fuzzy control, (8) is written as follows:

$$
\begin{gathered}
\dot{\mathrm{Z}}(\mathrm{t})=\mathrm{AZ}(\mathrm{t})+\mathrm{B}_{s}\left(\mathrm{~B}_{\mathrm{u}} \mathrm{U}(\mathrm{t})+\mathrm{B}_{\mathrm{r}} \mathrm{F}(\mathrm{t})\right) \\
\mathrm{F}_{f u}(\mathrm{t})=\mathrm{B}_{\mathrm{u}} \mathrm{U}(\mathrm{t})+\mathrm{B}_{\mathrm{r}} \mathrm{F}(\mathrm{t})
\end{gathered}
$$

To solve in state space we also need the following equation:

$$
\mathrm{y}=\mathrm{EZ}(\mathrm{t})+\mathrm{L}^{*} \mathrm{~F}_{f u}(\mathrm{t})
$$

Fuzzy control can be incorporated in a closed loop control system similar to conventional controllers. Fuzzy rule defines the relationship between fuzzy input and output based on a Mamdani model. The law contains two parts: introduction and results made of IF-THEN statements. Each rule is as follows:

$$
\mathrm{R}^{i}=\text { if } X_{1}=A_{i} \text { and } X_{2}=B_{i} \text { then } Y=C_{i}
$$

Where $i$ is number of control laws, $X_{1}$ and $X_{2}$ are introduction variables and $Y$ is result variable. Also $A_{i}, B_{i}$ and $C_{i}$ are linguistic values of fuzzy variables. In this study, the fuzzy controller design directly from the numerical and clear structure data model. Controller acts based on two input variables (velocity and displacement of the top floor), each having five triangular membership function (Figure 1a) and an

\begin{tabular}{|c|c|c|c|c|c|}
\hline \multirow{2}{*}{ 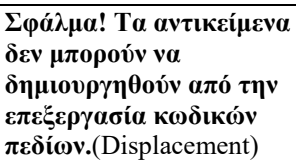 } & \multicolumn{5}{|c|}{ 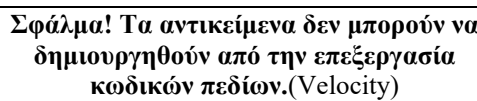 } \\
\hline & $\mathrm{LN}$ & $\mathrm{N}$ & $\mathrm{Z}$ & $\mathrm{P}$ & LP \\
\hline LP & NS & NS & NM & NL & NL \\
\hline $\mathrm{P}$ & NS & NM & NM & NM & NL \\
\hline$Z$ & PS & ZR & ZR & ZR & $\mathrm{NS}$ \\
\hline $\mathrm{N}$ & PL & PM & PM & PM & PS \\
\hline LN & $\mathrm{PL}$ & PL & PM & PS & PS \\
\hline
\end{tabular}
output variable (the active control) with seven triangular membership function (Figure 1b). The abbreviations of input and output membership functions for fuzzy variables to define the phase space are: $\mathrm{LP}=$ big and positive; $\mathrm{P}=$ positive; $\mathrm{Z}=$ null; $\mathrm{N}=$ negative; $\mathrm{LN}=$ large negative (for input variables), and $\mathrm{PL}=$ positive and large, $\mathrm{PM}=$ moderate positive; $\mathrm{PS}=$ Positive and small; $\mathrm{ZR}=$ null; $\mathrm{NL}=$ large negative; $\mathrm{NM}=$ high negative; $\mathrm{NS}=$ negative and small (variable output). Details of inference rules used in this study are shown in Table I.

TABLE I. FUZZY SYSTEM RULE BASE

Fuzzy controller uses the Mamdani method for making non-fuzzy to change the linguistic values to numerical and clear values. Linguistic output values between -1 and 1 must be multiplied by a factor to produce active control force.

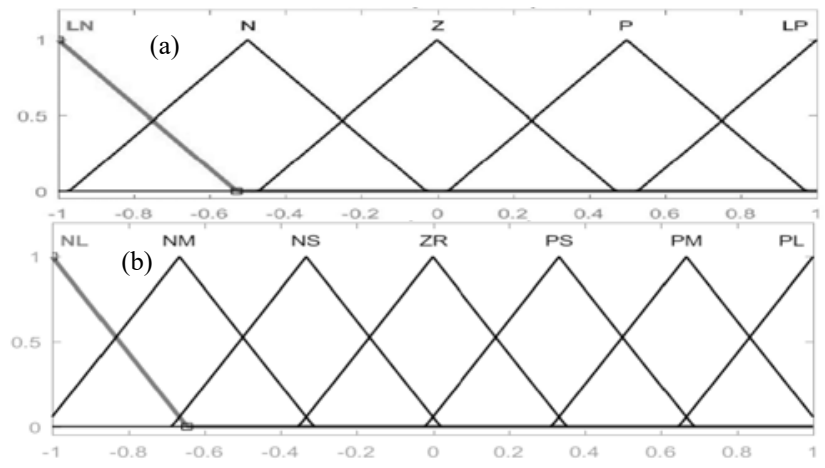

Fig. 1. (a) Membership functions of input variables (Displacement and Velocity), (b) Membership functions of the output variable (Active control force)

4) Pole allocation method

Unlike LQR algorithms, this algorithm solves structures inversely to encourage them to the desired response. This means that the structure's primary poles are determined from the beginning of the algorithm and then the system with respect to dampers increase the damping ratio of structures and by solving the main determinant of algorithm determines the new poles of structure so that systems moves toward increasing stability. Therefore new active structure poles define the 
system. However, changeable points in the algorithm should be considered from first variations advance through usable results for passive structural damper design. As a result, damping and stiffness values in the system are introduced only where there is permission to change them. To get answers to the (1), the equation of motion is transmitted to state-space.

$$
\dot{\mathrm{Z}}(\mathrm{t})=\mathrm{AZ}(\mathrm{t})+\mathrm{B}_{\mathrm{u}} \mathrm{U}(\mathrm{t})+\mathrm{B}_{\mathrm{r}} \mathrm{x}_{g}(\mathrm{t})
$$

Eigenvalues of matrix A are as follows:

$$
\rho_{i}=-\xi_{i} \omega_{i} \pm \omega_{i} \sqrt{1-\xi_{i}^{2}} j ; \quad j=\sqrt{-1}
$$

In (13), $\mathrm{U}(\mathrm{t})$ is as follows:

$$
\mathrm{U}(\mathrm{t})=-\mathrm{GZ}(\mathrm{t})
$$

By combining (13) and (15), we have:

$$
\dot{\mathrm{Z}}(\mathrm{t})=\mathrm{AZ}(\mathrm{t})+\mathrm{B}_{\mathrm{u}}(-\mathrm{GZ}(\mathrm{t}))+\mathrm{B}_{\mathrm{r}} \mathrm{f}(\mathrm{t})
$$

Considering $\mathrm{A}^{*}=\mathrm{A}-\mathrm{B}_{\mathrm{u}} \mathrm{G}(13)$ is expressed as follows:

$$
\dot{Z}(\mathrm{t})=\mathrm{A}^{*} \mathrm{Z}(\mathrm{t})+\mathrm{B}_{\mathrm{r}} \mathrm{f}(\mathrm{t})
$$

Eigenvalues of matrix $\mathrm{A}^{*}$ are as follows:

$$
\rho_{i}=-\xi_{i}^{*} \omega_{i} \pm \omega_{i} \sqrt{1-\xi_{i}^{* 2}} j ; \quad j=\sqrt{-1}
$$

By increasing the amount $\xi$ to $\xi^{*}$ and considering $G$ unknown, $\mathrm{G}$ is acquired using place command in Matlab software and thus the amount of control force is obtained. To solve the problem in state space we also need following equation:

$$
y=E Z(t)+L f(t)
$$

\section{B. Uncontrolled structure}

Equation of motion for multi-floor buildings with shear frame model without a controller is as follows:

$$
\mathrm{Mx}(\mathrm{t})+\mathrm{C} \dot{\mathrm{x}}(\mathrm{t})+\mathrm{Kx}(\mathrm{t})=-\mathrm{Mr}_{g}(\mathrm{t})
$$

After obtaining the response of motion equation (20), we transmit the equation of motion to state-space.

$$
\dot{\mathrm{Z}}(\mathrm{t})=\mathrm{AZ}(\mathrm{t})+\mathrm{B}_{\mathrm{r}} \mathrm{x}_{g}(\mathrm{t})
$$

In addition to solve in the state space equation (21) is needed in addition to equation (22).

$$
\mathrm{y}=\mathrm{EZ}(\mathrm{t})+\mathrm{L} \mathrm{x}_{g}(\mathrm{t})
$$

\section{NUMERICAL EXAMPLE}

Three buildings with different heights (low height of 5 floors, the average height of 10 floors and high height of 20 floors) are taken into account. For the 5 and 10 floor buildings, the mass of each floor is $1 * 10^{5} \mathrm{Kg}$ and the stiffness of each floor is $5^{*} 10^{7} \mathrm{~N} / \mathrm{m}$ and a structural damping ratio of $\xi=0.05$ is considered.

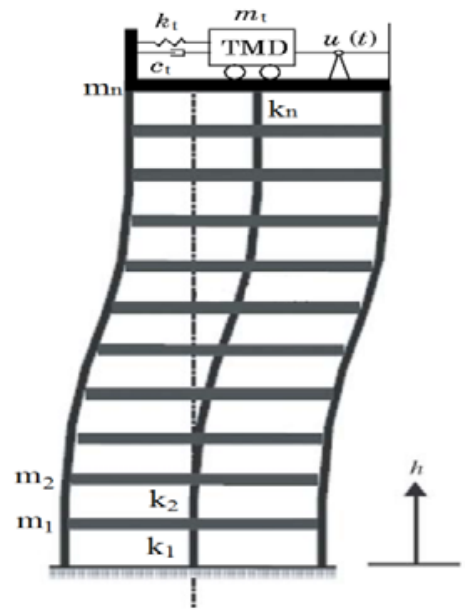

Fig. 2. $\mathrm{N}$ floor building with shear frame and an ATMD in roof

In these two cases, an ATMD is installed on the top floor (roof) to reduce the structural response (Figure 2). Its mass is equal to $\mathrm{m}_{\mathrm{t}}=5^{*} 10^{4} \mathrm{Kg}$. Since the first structure frequency is crucial for the specification of ATMD, stiffness of ATMD is calculated from the following equation:

$$
\mathrm{k}_{\mathrm{t}}=\mathrm{m}_{\mathrm{t}} \cdot \mathrm{w}_{1}^{2}
$$

Where $\mathrm{w}_{1}$ is the first frequency structures. ATMD damping ratio equal to that taken into account, since the damping $\xi_{\mathrm{t}}=0.05$ ATMD to be achieved as follows:

$$
\mathrm{c}_{\mathrm{t}}=2 \xi_{\mathrm{t}} \cdot \mathrm{m}_{\mathrm{t}} \cdot \mathrm{w}_{1}
$$

The only difference in the 20 floor building is the stiffness of floors which is considered equal to $8 * 108 \mathrm{~N} / \mathrm{m}$. For each building, three control methods have been used. The first control method employed is the linear quadratic regulator method (LQR). In all cases $\mathrm{R}=1 * 10-4$ and $\mathrm{Q}=\alpha \mathrm{I}, \alpha=1 * 109$ are considered in relation. The higher $\alpha$ increases control force. The results showed that for amounts larger than $\alpha=1 * 10^{9}$ the controlling force does not increase and this is a disadvantage to this approach. The second control method employed is fuzzy control. In this method the response of the structure as displacement and velocity of top floor are used as fuzzy logic inputs. Control force output is between -1 and 1 . It should be multiplied by a factor to result to a larger control force. This factor is considered equal to $1 * 10^{6}$ in all cases. The final method employed is pole assignment, with a structural damping of $\xi=0.05$, increased to $\xi=0.15$ for the first two buildings and to $\xi=0.07$ for the 20 floor building. The ultimately gain matrix $G$ and control force each time step is calculated with the relationship $U(t)=-G Z(t)$. New damping ratios were calculated in a way that greatest reduction occurs in floor displacements. Two earthquake records corresponding to Loma Prieta and Northridge earthquakes were used for all states. These accelerograms can be seen in Figures 3 and 4. .. 
The structural response results of Northridge earthquake is further explained in detail with tables and graphs.

The impact of the Northridge earthquake is considered in Table II for three 5-floor buildings where the three methods were compared. Maximum ATMD controlling force in these three methods shows that with the fuzzy control method a large control force can be produced. A weaker control force is created with the other two methods. Also, the displacement of the controlled mode to uncontrolled in all floors and for all three control methods is under one, which shows a decrease in displacement for all control methods. Because of the large control force in fuzzy method, the controlled to uncontrolled mode displacement ratio is very low and there is $50 \%$ to $70 \%$ reduction in movement. This reduction is greater on the upper floors. The reduction in other two methods is about $20 \%$.

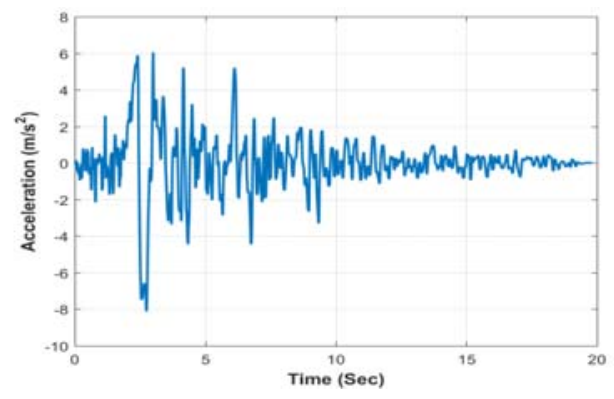

Fig. 3. Northridge earthquake accelerograms

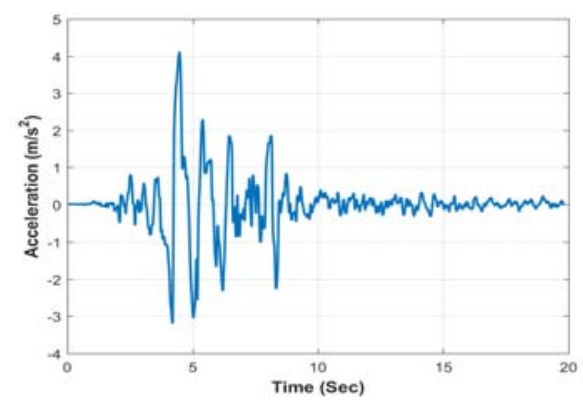

Fig. 4. Loma Prieta earthquake accelerograms

TABLE II. DISPLACEMENT RATIO (UNCONTROLLED TO CONTROLLED STATE) AND MAXIMUM CONTROL FORCE IN THE 5 FLOOR BUILDING

\begin{tabular}{|c|c|c|c|}
\hline State & 1 & 2 & 3 \\
\hline Control Algorithm & LQR & Fuzzy & Pole allocation \\
\hline Maximum control force (kN) & 10240 & 47210 & 5370 \\
\hline Floor 1 & 0.82 & 0.44 & 0.77 \\
\hline Floor 2 & 0.83 & 0.43 & 0.79 \\
\hline Floor 3 & 0.84 & 0.40 & 0.81 \\
\hline Floor 4 & 0.83 & 0.36 & 0.82 \\
\hline Floor 5 & 0.83 & 0.32 & 0.84 \\
\hline
\end{tabular}

In Figure 5, controlled and non-controlled displacement time-history chart of first and fifth floors of a 5-floor building with the LQR procedure can be observed. In both floors variation range of controlled state is less than that of the uncontrolled state. LQR control method reduced the initial peaks of graph up to $20 \%$ and this reduction increased in further time steps. This is a good result, although the initial peaks of graph reduced slightly, high displacement reduction in next time steps, causes less cyclic structure fatigue.

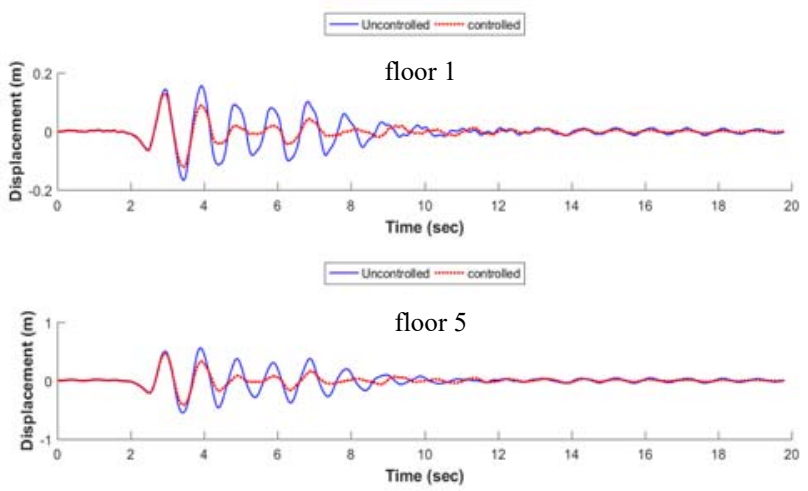

Fig. 5. Time-history graph of controlled and non-controlled states of Mode 1

In Figure 6, the force control generated by the fuzzy logic can be observed at different time steps. History shows that the force is very logical control force and corresponding actions earthquake is generated. The maximum control force is found to be $5 * 104 \mathrm{KN}$. Time-history graph for the controlling force in LQR method can be observed in Figure 6. Maximum experienced control force is $1 * 10^{4} \mathrm{KN}$. In Figure 7, the maximum absolute displacement of various floors for controlled and non-controlled states of a 5-floor building with $\mathrm{LQR}$ method is presented. In this figure reduced displacements for each floor are presented, the reduction is larger for upper floors. According to Figure 8, the variation range of controlled state is less than that of the uncontrolled state on both floors which reflects the decreasing displacement in fuzzy method for five floor building. The Fuzzy control method reduces the displacement of steps in same size and approximately the same decrease can be observed. In Figure 9, the control force generated by the fuzzy logic control at different time steps can be observed. The history of control force shows that the force is very logical and control force is generated corresponding to applied earthquake. The maximum experienced control force is $5 * 104 \mathrm{KN}$. Stronger quake produces greater control force.

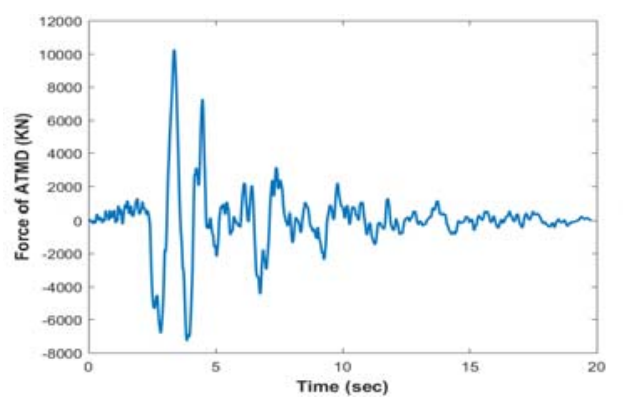

Fig. 6. Time- history graph for control force in LQR method of mode 1

In Figure 10, the maximum absolute displacement of different floors in controlled and uncontrolled states of mode 2 
can be observed. Reduced displacement for each floor is visible, while the reduction in upper floors is more for the fuzzy control method. The variation range of controlled state is less than that of the uncontrolled state which shows a reduction in displacement for pole allocation method of the 5-floor building. Displacement reduction in pole allocation control method in all steps is approximately the same as LQR method. In Figure 12, the control force produced by the pole allocation method in different time steps can be observed. The maximum experienced control force is $5^{*} 10^{3} \mathrm{KN}$. In Figure 13, the maximum absolute displacement of different floors in controlled and uncontrolled state of mode 3 is shown. Reduction of displacement in all floors is observed in this Figure. Reduced displacement for pole allocation method in all floors is observed, while the reduction in the upper floors is larger.

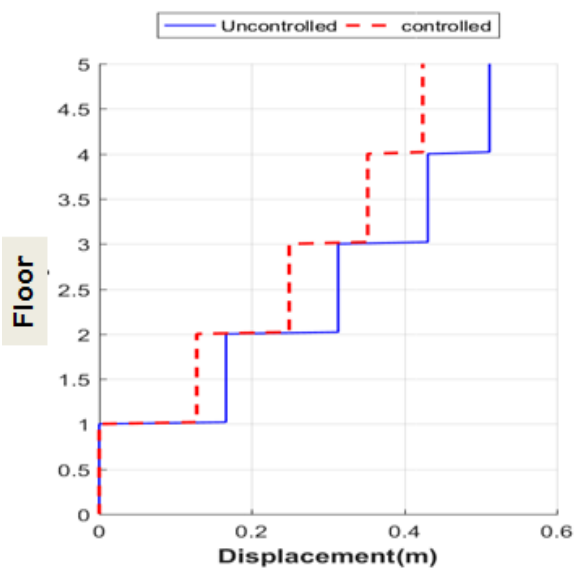

Fig. 7. The maximum absolute displacement in different floors for controlled and uncontrolled states of mode 1
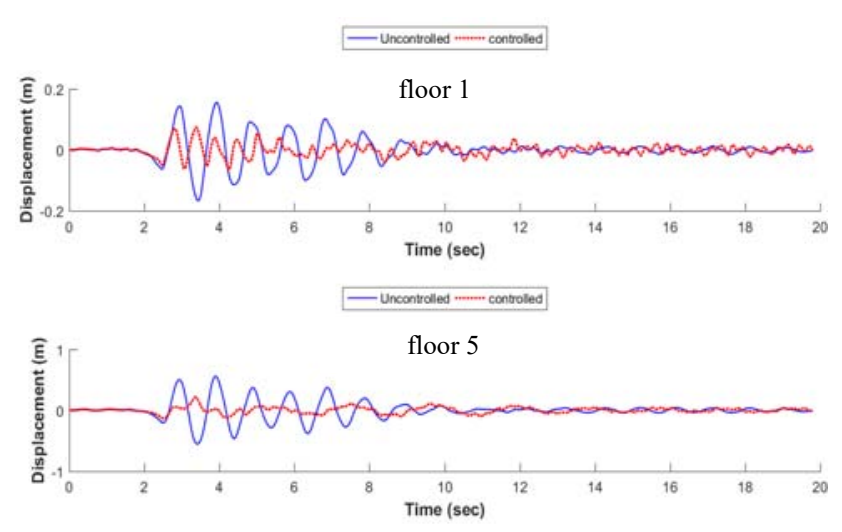

Fig. 8. Time-history graph of controlled and uncontrolled state for mode 2

As shown in Table III, in the case of 4 to 6 with 10 floors the displacement of controlled state to uncontrolled state in all floors and for all three control methods is the same that shows a decrease in displacement for all control methods and also the maximum control force is about the same in all three control methods. But control force generated by the LQR method is a bit lower which cause reduction in displacement about 10 to
$30 \%$. Floor displacement reduction in fuzzy method is 25 to $40 \%$. In pole allocation method this reduction is 20 to $35 \%$. Weak performance of fuzzy method compared to previous state is because stiff floors in a 10 floor building, in comparison to mass and stiffness of a 5-floor building remained unchanged and the frequency and period of structure has changed.

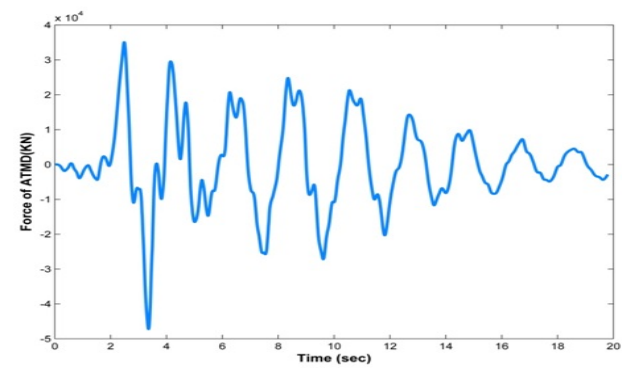

Fig. 9. Time-history graph for control force in fuzzy method of mode 2

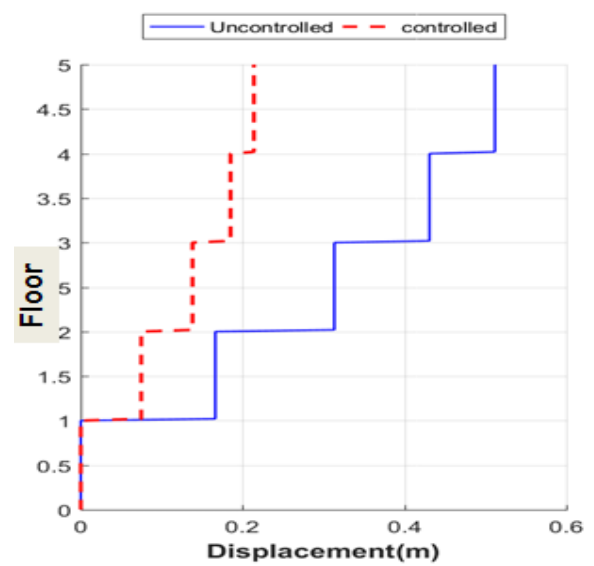

Fig. 10. Maximum absolute displacement in different floors in controlled and uncontrolled state of mode 2

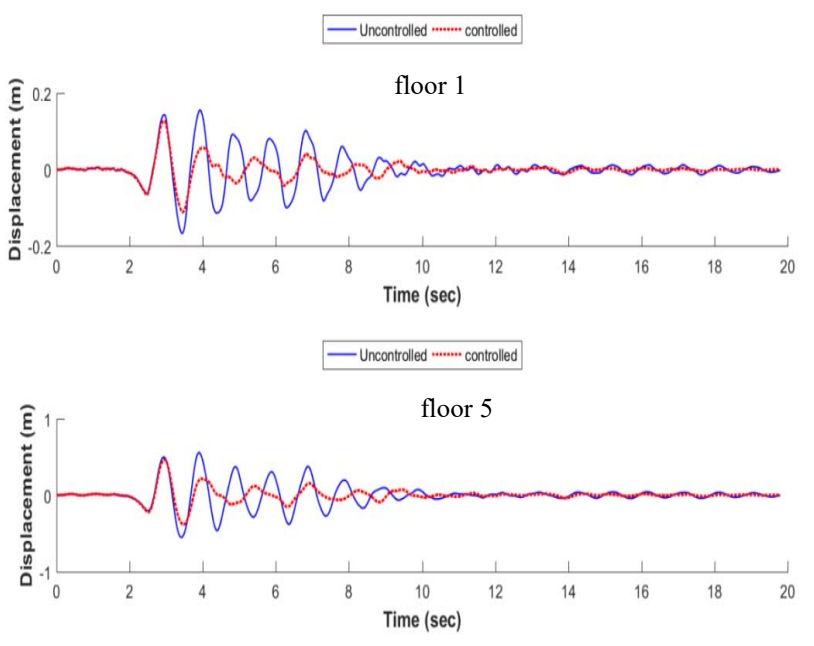

Fig. 11. Time-history graph of controlled and uncontrolled state for mode 3 


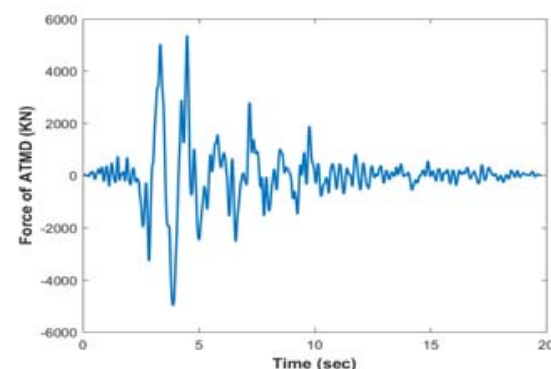

Fig. 12. Time-history graph for control force in pole allocation method of mode 3

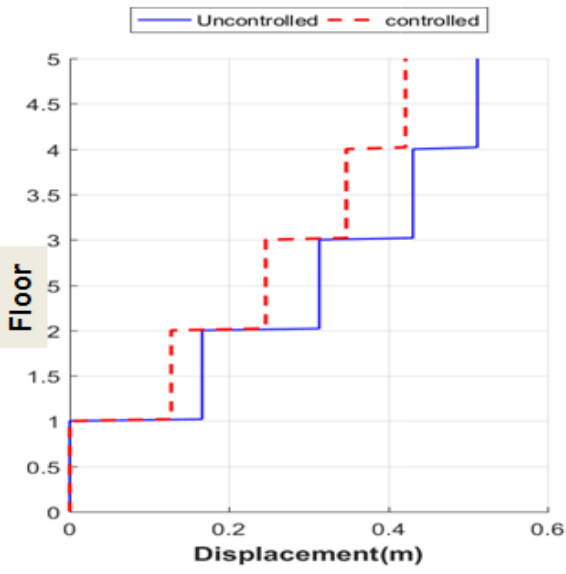

Fig. 13. Maximum absolute displacement in different floors in controlled and uncontrolled state of mode 3

TABLE III. DISPLACEMENT RATIO (UNCONTROLLED TO CONTROLLED STATE) AND MAXIMUM CONTROL FORCE IN 10 FLOOR BUILDING.

\begin{tabular}{|c|c|c|c|}
\hline State & 4 & 5 & 6 \\
\hline Control algorithm & LQR & Fuzzy & Pole allocation \\
\hline Maximum control force $(\mathrm{kN})$ & 5440 & 7970 & 7750 \\
\hline Floor 1 & 0.71 & 0.70 & 0.65 \\
\hline Floor 2 & 0.73 & 0.65 & 0.66 \\
\hline Floor 3 & 0.76 & 0.61 & 0.67 \\
\hline Floor 4 & 0.81 & 0.61 & 0.69 \\
\hline Floor 5 & 0.87 & 0.69 & 0.70 \\
\hline Floor 6 & 0.91 & 0.73 & 0.70 \\
\hline Floor 7 & 0.91 & 0.75 & 0.73 \\
\hline Floor 8 & 0.90 & 0.74 & 0.76 \\
\hline Floor 9 & 0.90 & 0.72 & 0.79 \\
\hline Floor 10 & 0.90 & 0.70 & 0.81 \\
\hline
\end{tabular}

In Figures 14-16, the reduction of maximum floor displacements in uncontrolled and controlled state of a 10-floor buildings can be seen. In all three control methods for 10 -floor building, displacement reduction for all floors is seen that the reduction in the upper floors is more. The fuzzy method shows weak performance, because of the increasing stiffness of floors in comparison to the 5-floor building. In Table IV, states 7 to 9 with 20 floors, maximum ATMD control force in three considered methods is shown that a large control force is created by the fuzzy method and a weaker control force is created by the other two methods. The control force generated by the LQR is slightly larger than that of pole allocation. Displacement reduction is about $13 \%$ for LQR, 35 to $50 \%$. For the fuzzy method and $11 \%$ for the pole allocation method.

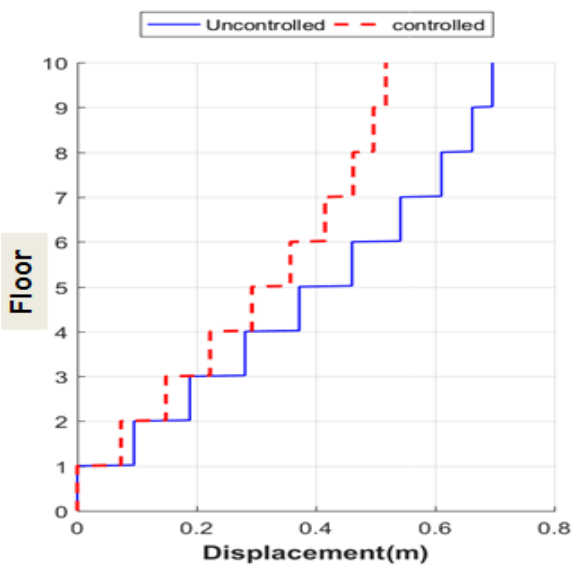

Fig. 14. Maximum absolute displacement of different floors in controlled and uncontrolled state of mode 4

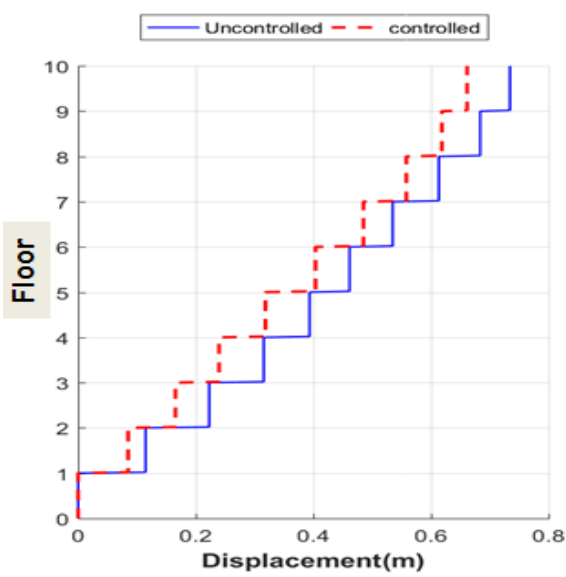

Fig. 15. Maximum absolute displacement of different floors in controlled and uncontrolled state of mode 5

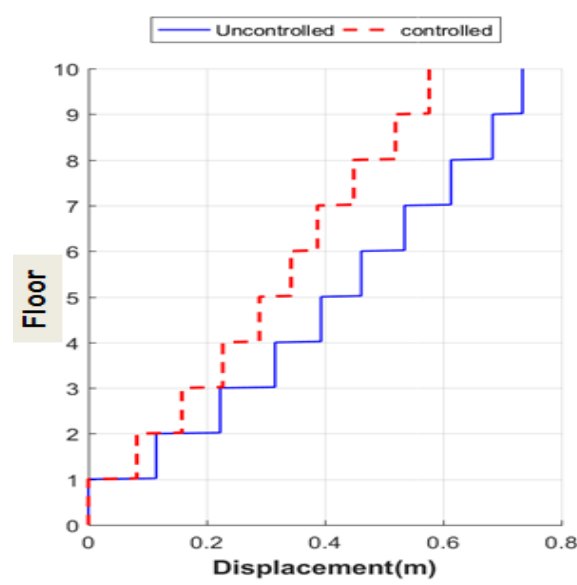

Fig. 16. Maximum absolute displacement of different floors in controlled and uncontrolled state of mode 6 
TABLE IV. DISPLACEMENT RATIO (UNCONTROLLED TO CONTROLLED STATE) AND MAXIMUM CONTROL FORCE IN 20 FLOOR BUILDING.

\begin{tabular}{|c|c|c|c|}
\hline State & 7 & 9 & 8 \\
\hline $\begin{array}{c}\text { Control } \\
\text { Algorithm }\end{array}$ & LQR & $\begin{array}{c}\text { Pole } \\
\text { allocation }\end{array}$ & Fuzzy \\
\hline $\begin{array}{c}\text { Maximum } \\
\text { Control } \\
\text { Force }\end{array}$ & 12760 & 6010 & 62440 \\
\hline Floor 1 & 0.87 & 0.89 & 0.66 \\
\hline Floor 2 & 0.87 & 0.89 & 0.66 \\
\hline Floor 3 & 0.88 & 0.89 & 0.66 \\
\hline Floor 4 & 0.88 & 0.89 & 0.66 \\
\hline Floor 5 & 0.88 & 0.89 & 0.65 \\
\hline Floor 6 & 0.88 & 0.89 & 0.65 \\
\hline Floor 7 & 0.87 & 0.89 & 0.65 \\
\hline Floor 8 & 0.87 & 0.88 & 0.64 \\
\hline Floor 9 & 0.87 & 0.88 & 0.63 \\
\hline Floor 10 & 0.87 & 0.88 & 0.62 \\
\hline Floor 11 & 0.86 & 0.87 & 0.61 \\
\hline Floor 12 & 0.86 & 0.87 & 0.60 \\
\hline Floor 13 & 0.86 & 0.87 & 0.59 \\
\hline Floor 14 & 0.86 & 0.87 & 0.58 \\
\hline Floor 15 & 0.86 & 0.87 & 0.57 \\
\hline Floor 16 & 0.86 & 0.87 & 0.56 \\
\hline Floor 17 & 0.86 & 0.87 & 0.55 \\
\hline Floor 18 & 0.86 & 0.87 & 0.54 \\
\hline Floor 19 & 0.86 & 0.87 & 0.53 \\
\hline Floor 20 & 0.86 & 0.87 & 0.53 \\
\hline
\end{tabular}

Figures 17-19 show the reduction of the maximum displacement of floors in uncontrolled and controlled state of a 20 -floor building. In all three control methods for 20-floor building reduced displacement for all floors can be seen that the reduction in the upper floors is more. Meanwhile, the fuzzy method shows the best performance. Tables V-VII 7 show the displacement of controlled state to uncontrolled state and the maximum control force in 5, 10 and 20 floor buildings under Loma Prieta earthquake. Same results of Northridge earthquake can be seen for Loma Prieta.

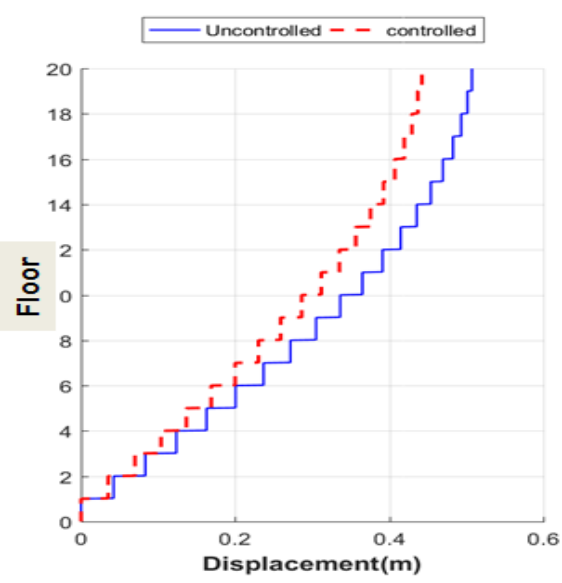

Fig. 17. Maximum absolute displacement of different floors in controlled and uncontrolled state of mode 7

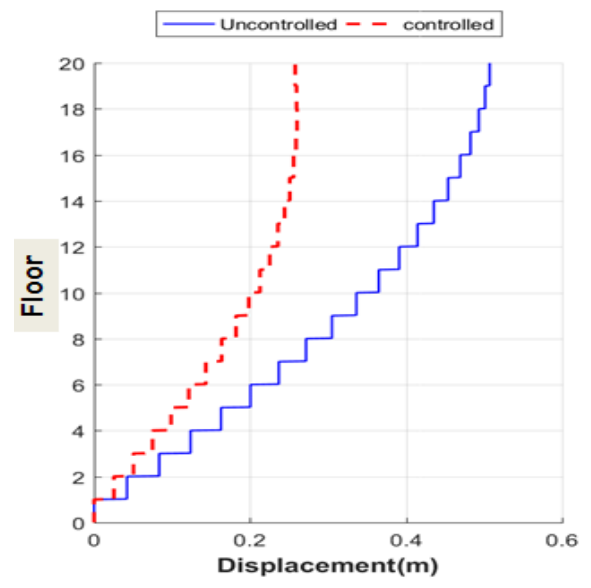

Fig. 18. Maximum absolute displacement of different floors in controlled and uncontrolled state of mode 8

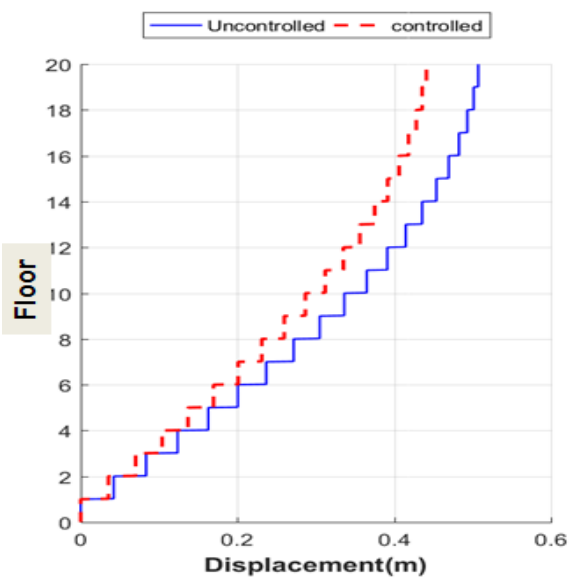

Fig. 19. Maximum absolute displacement of different floors in controlled and uncontrolled state of mode 9

In Figures 20-22 with changing mass of floors from 20\% less than the original mass to $20 \%$ more than the original mass, its impact on reduction of floor displacements in uncontrolled and controlled states with three methods is shown. The results show that all three methods of control are stable in different masses and random change of floor masses we can safely reduce structural displacement. In 5-floor buildings, as shown in Figure 20, it can be seen the displacement of structures for various masses decreased in all three control methods, and also increasing floor masses, the reduction of structural displacement is reduced. Graphs of displacement variation in three control methods are nearly parallel to displacement variation graph of uncontrolled displacement. As can be seen fuzzy control method has high performance in 5-floor building.

According to Figure 21, in 10-floor buildings, the displacement of structures for various masses decreased in all three control methods and displacement variation with mass changes is very small. In LQR method, same results are observed, and despite the reduced displacement, the displacement variation graph is unchanged. In pole allocation method with mass increase, displacement is slightly reduced. 
The greatest effect of floor mass change in 10 floor buildings is in fuzzy control method that the mass increase causes a strong increase in displacement. The increase from $80 \%$ of mass to $120 \%$ of the mass is about $25 \%$. So it is possible that with excess increase in floor masses, fuzzy logic method in 10-floor building lose its efficiency.

TABLE V. DISPLACEMENT RATIO (UNCONTROLLED TO CONTROLLED STATE) AND MAXIMUM CONTROL FORCE IN 5 FLOOR BUILDING.

\begin{tabular}{|c|c|c|c|}
\hline State & 1 & 2 & 3 \\
\hline Control Algorithm & LQR & Fuzzy & Pole allocation \\
\hline Maximum control force $(\mathrm{kN})$ & 5160 & 20800 & 2820 \\
\hline Floor 1 & 0.66 & 0.24 & 0.58 \\
\hline Floor 2 & 0.66 & 0.23 & 0.59 \\
\hline Floor 3 & 0.68 & 0.21 & 0.61 \\
\hline Floor 4 & 0.69 & 0.18 & 0.63 \\
\hline Floor 5 & 0.71 & 0.16 & 0.65 \\
\hline
\end{tabular}

TABLE VI. DISPLACEMENT RATIO (UNCONTROLLED TO CONTROLLED STATE) AND MAXIMUM CONTROL FORCE IN 10 FLOOR BUILDING.

\begin{tabular}{|c|c|c|c|}
\hline State & 4 & 5 & 6 \\
\hline Control Algorithm & LQR & Fuzzy & Pole allocation \\
\hline Maximum control force $(\mathrm{kN})$ & 2500 & 6280 & 4050 \\
\hline Floor 1 & 0.91 & 0.72 & 0.89 \\
\hline Floor 2 & 0.89 & 0.71 & 0.86 \\
\hline Floor 3 & 0.85 & 0.70 & 0.82 \\
\hline Floor 4 & 0.80 & 0.68 & 0.77 \\
\hline Floor 5 & 0.78 & 0.66 & 0.74 \\
\hline Floor 6 & 0.78 & 0.65 & 0.71 \\
\hline Floor 7 & 0.77 & 0.64 & 0.69 \\
\hline Floor 8 & 0.77 & 0.63 & 0.67 \\
\hline Floor 9 & 0.77 & 0.61 & 0.67 \\
\hline Floor 10 & 0.76 & 0.59 & 0.68 \\
\hline
\end{tabular}

TABLE VII. DISPLACEMENT RATIO (UNCONTROLLED TO CONTROLLED STATE) AND MAXIMUM CONTROL FORCE IN 20 FLOOR BUILDING.

\begin{tabular}{|c|c|c|c|}
\hline State & 7 & 8 & 9 \\
\hline Control algorithm & LQR & Fuzzy & Pole allocation \\
\hline Maximum Control Force $(\mathrm{kN})$ & 6270 & 30990 & 3000 \\
\hline Floor 1 & 0.84 & 0.31 & 0.82 \\
\hline Floor 2 & 0.84 & 0.30 & 0.82 \\
\hline Floor 3 & 0.84 & 0.30 & 0.82 \\
\hline Floor 4 & 0.84 & 0.29 & 0.82 \\
\hline Floor 5 & 0.83 & 0.29 & 0.82 \\
\hline Floor 6 & 0.83 & 0.28 & 0.82 \\
\hline Floor 7 & 0.83 & 0.28 & 0.82 \\
\hline Floor 8 & 0.83 & 0.27 & 0.82 \\
\hline Floor 9 & 0.83 & 0.27 & 0.83 \\
\hline Floor 10 & 0.83 & 0.26 & 0.83 \\
\hline Floor 11 & 0.84 & 0.26 & 0.83 \\
\hline Floor 12 & 0.84 & 0.25 & 0.83 \\
\hline Floor 13 & 0.84 & 0.25 & 0.83 \\
\hline Floor 14 & 0.84 & 0.26 & 0.83 \\
\hline Floor 15 & 0.84 & 0.27 & 0.83 \\
\hline Floor 16 & 0.84 & 0.28 & 0.84 \\
\hline Floor 17 & 0.84 & 0.29 & 0.84 \\
\hline Floor 18 & 0.84 & 0.30 & 0.84 \\
\hline Floor 19 & 0.84 & 0.31 & 0.84 \\
\hline Floor 20 & 0.84 & 0.32 & 0.85 \\
\hline
\end{tabular}

According to Figure 22 in 20-floor buildings, displacement of structures for various masses decreased in all three control methods, in controlled and uncontrolled case and increasing mass increases displacement. This change is less in fuzzy control method. This shows that the fuzzy method has very high performance in high-rise buildings. Also fuzzy method drastically reduces the structural response of high rise building.

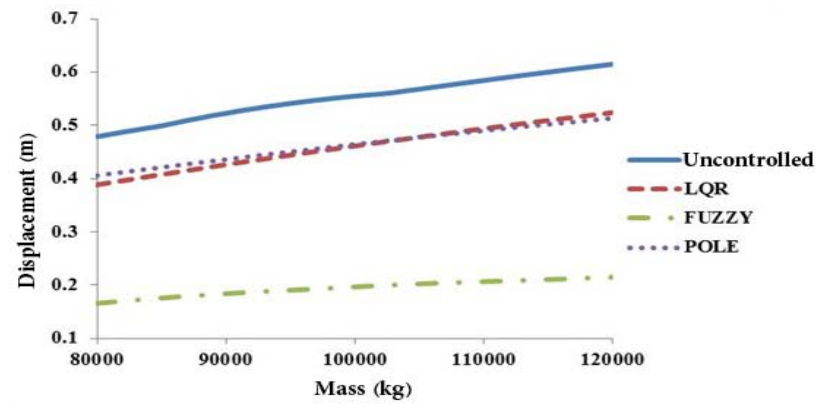

Fig. 20. Maximum displacement change of the top floor of 5-floor buildings to change floor masses.

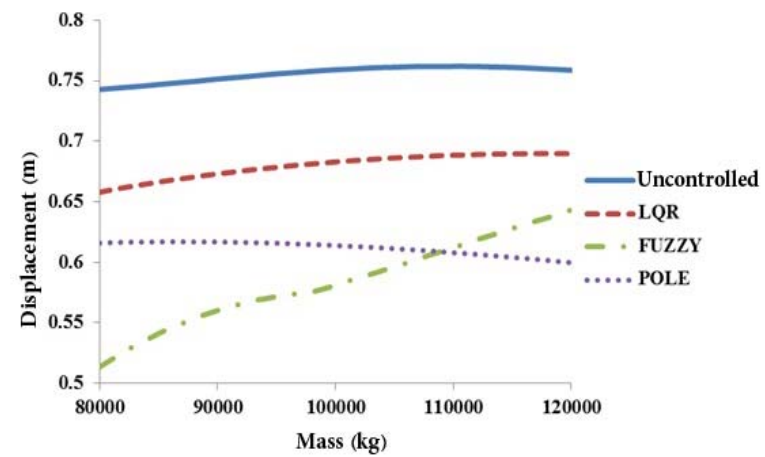

Fig. 21. Maximum displacement change of the top floor for 10-floor buildings to change of floor masses.

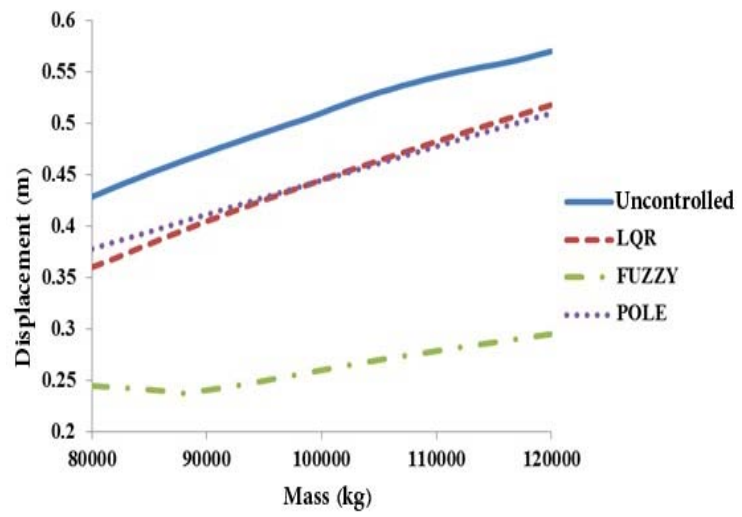

Fig. 22. Maximum displacement change of the top floor for 20-floor buildings to change of floor masses.

\section{CONCLUSION}

All three control methods used in this study (LQR, fuzzy and allocation pole) for ATMD reduces the structural response. But fuzzy control method drastically reduced floor displacement up to $80 \%$. Further, in LQR and pole allocation methods limited control force was conducted. Therefore, the 
fuzzy control method provides the best results. However, if the controlling force is greater than a specific amount, rather than reducing floor displacement, increases them. It should be noted that the fuzzy control method performed best in the case of high-rise buildings.

\section{REFERENCES}

[1] S. Thenozhi, W. Yu, "Advances in modeling and vibration control of building structures", Annual Reviews in Control, Vol. 37, No. 2, pp. 346-364, 2013

[2] M. Al-Dawod, B. Samali, K. Kwok, F. Naghdy, "Fuzzy controller for seismically excited nonlinear buildings", Journal of Engineering Mechanics, Vol. 130, No. 4, pp. 407-415, 2004

[3] R. Guclu, H. Yazici, "Vibration control of a structure with ATMD against earthquake using fuzzy logic controllers", Journal of Sound and Vibration, Vol. 318, No. 1, pp. 36-49, 2008

[4] S. M. Nigdeli, M. H. Boduroglu, "Active Tendon Control of Torsionally Irregular Structures under Near - Fault Ground Motion Excitation", Computer - Aided Civil and Infrastructure Engineering, Vol. 28, No. 9 , pp. 718-736, 2013

[5] T. Kobori, R. Minai, "Analytical study on active seismic response control", Transactions, Architectural Institute of Japan, Vol. 66, No. 2, pp. 256-257, 1960 